\title{
The Influence of the Education Level on the Standards in South-Eastern European Countries with the Focus of Macedonia and the Age of the Employees
}

\author{
Sreten Miladinoski \\ MIT University - Skopje, Faculty of Management, Macedonia \\ Email: sreten.miladinoski@gmail.com \\ Sanja Nikolic \\ MIT University - Skopje, Faculty of Management, Macedonia \\ Email: sanja.nikolic777@gmail.com
}

Ibish Mazreku

University Haxhi Zeka, Faculty of Business, Kosovo Email: ibish.mazreku@unhz.eu

\section{Doi:10.5901/ajis.2015.v4n2s1p183}

\section{Abstract}

\begin{abstract}
The era of knowledge brings new changes that are seen in the rapid advance and development of science, engineering and technology, which in turn entails changes in society, as well as on the market, creating new "rules of the game" to which organizations would have to respond. In these conditions of the dynamic environment, the knowledge management is considered as a strategy to gain competitive advantage. The objective of the research is to examine the significance and the influence of the education level and the age of the employees on the knowledge management implementation. The research was conducted on the telecommunication market in the Republic of Macedonia which is characterized as an open and dynamic market. The research was carried out in 10 companies, to a sample of 100 respondents - employees in these companies. The results show the awareness of the employees for the need for constant improvement of the professional knowledge. Also, the education level and the age of the employees have influence of their attitude about several factors of knowledge management implementation which were researched.
\end{abstract}

Keywords: dynamic environment, knowledge management, telecommunication market, level of education and age of employees

\section{Introduction}

Regarding the current conditions on the open market, it can be said that the organizations need new management concept to appropriately respond to these conditions.

The dynamic environment and the struggle for survival in it, made organizations turn towards continuous and fast acquisition and maintenance of today's most powerful resource - knowledge.

The organizational knowledge represents the overall knowledge of the employees, a specific property of the organization, above all due to its intangibility, which is not the case with buildings, land, equipment, etc. It constitutes the knowledge of the employees - the human resources. The knowledge of the employees, their skills and abilities determine the way in which the organization operates.

The organizational knowledge is in fact creating value through practical application of knowledge - to turn knowledge into products, services or processes which will bring new value to the organization.

\section{The Significance of Knowledge Management as a Strategy for Acquiring Competitive Advantage at the Current Conditions on the Open Market}

The era of knowledge brings new changes that are seen in the rapid advance and development of science, engineering and technology, which in turn entails changes in society, as well as on the market, creating new "rules of the game" to which organizations would have to respond. These changes are especially visible in the last ten years, and the following 
can be distinguished in brief (Slavković M., 2006, pp. 180-199):

- Knowledge becomes a crucial issue for the success of the organization. Competitive advantage is built through managing and connecting employees that possess specific knowledge and skills.

- The time for decision making is significantly shortened. The dynamic environment and the changes occurring in it do not leave space to the organization for long consideration. Timely, quick reactions that will follow current changes are needed.

- Relations among employees are becoming very complex. The new conditions of work emphasize the importance of independence, communication skills, and the ability to build and maintain good relations with the employees in the organization. Virtual organizations are a common occurrence, which reduces the need for physical contact of the employees.

- The information and communication technologies are increasingly being incorporated into the interactions among people, as well as into business transactions. People have become dependent on technology to such an extent that literacy is no longer reading and writing, but work on computers.

Knowledge management is a concept that has the knowledge in the focus and should continuously implement within the organization. Considering the current condition on the open market, named above, we see the need of knowledge management as a strategy to gain competitive advantage. We can say that, in the time of knowledge economy, knowledge management should provide innovation, improvement of the products and services, reduction of the costs, reduction of the employees' fluctuations, enhancement of the processes and procedures etc. in the organization.

\section{The Objective of the Research}

This research examines the knowledge management implementation in correlation with the education level and the age of the employees. The objective of the research is to illustrate the connection between the education level and the age of the employees on one side, and the relevant factors of knowledge management implementation, on the other. In this respect it would be examined how different education level and age influence on the knowledge management implementation, regarding the organizational culture, human resource management, motivation system of the organization etc.

\section{Methodology}

\subsection{Participant}

The research was conducted in 10 companies on the telecommunication market in the Republic of Macedonia, to a sample of 100 respondents - employees in these companies.

\subsection{Materials and instruments}

The questionnaire that was given to respondents was formed with multiple choice questions, using the Likert scale. The respondents had to choose one from five offered alternatives which expressed their level of agreement or disagreement for a series of statements.

The analysis of the results was made using $x^{2}$ test in purpose to underline the correlation between the education level and the age of the respondents and their answers on the questions. Also, Spearman's coefficient is been used to illustrate whether the influence of the education level and the age of the respondents on their answers is directly or inversely proportional.

\subsection{Procedure}

The employees in the organizations on the telecommunication market were asked to respond the questionnaire in purpose of getting the needed information for the thesis. They answered the questionnaire. The collected results were systematized, processed and discussed. 


\subsection{Constraints}

Proposed answers are given to respondents. Most often they are subjectively determined.

\section{Results and Discussion}

The majority of respondents who participated in the survey, are between 26 and 36 years old, immediately followed by respondents who are between 36 and 45 years old with $25 \%$. $7 \%$ of the respondents who answered the questionnaire are aged to 25 years, and only $3 \%$ of the respondents are between 46 and 55 years old, which indicates a relatively young population working in the organizations that are the subject of this research.

Regarding the qualification of the employees, the majority of the respondents are highly educated $-63 \%$, and the percentage of those who have completed their master studies as well, is also high $-30 \%$ of the respondents. Only $7 \%$ of the respondents have completed their secondary school education.

The results show significant correlation and direct proportional influence between the age of the respondents and their attitude about the process of globalization which increased the competiveness on the telecommunication market in the Republic of Macedonia. This means that the older respondents think that the competition on the telecommunication market is increased. On the other side, there is significant correlation and inverse proportional influence between the education of the respondents and their attitude about this question. The respondents with higher level of education don't think that the competition on the telecommunication market is increased. Regarding this, it could be concluded that the older employees felt the change occurred on the market, but the employees with higher education level don't think that the competition is increased because they feel safe and competitive with their knowledge acquired in the process of education.

The results show is significant correlation between the age of the employees and their attitude about the role of the human resource management in the competitive conditions on the open market. The influence is directly proportional, which means that the older employees emphasize the importance of the human resource management the competitive conditions on the open market.

There is significant correlation between the education of the employees and their attitude if the managers undertake activities to improve the knowledge and skills in the organization. The results show that the respondents with higher level of education recognize that managers undertake activities to improve the knowledge and skills in the organization.

The results show significant correlation between the age of the employees and their attitude about the need of participation on the professional trainings and courses in purpose to improve and upgrade the knowledge and the skills. Regarding the inverse proportional influence, it can be concluded that the younger employees recognize the need of participation on the professional trainings and courses in purpose to improve and upgrade the knowledge and the skills.

The inverse proportional influence occurs between the education of the employees and their attitude about the need of constant improvement of their knowledge in the field of their profession. The employees with the lower education level recognize the need of constant improvement of the knowledge in the field of their profession.

There is significant correlation and inverse proportional influence between the age of the employees and their attitude about the need of constant improvement of their knowledge outside of the field of their profession. This means that the younger respondents recognize need of constant improvement of their knowledge outside of the field of their profession.

There is significant correlation between the age of the employees and their attitude about the knowledge gained on the professional trainings and courses which should help them in decision making process. Regarding the direct proportional influence, it can be concluded that the older employees think that knowledge gained on the professional trainings help them in decision making process.

The results show significant correlation between the education of the employees and their participation in the problem solving in the organization by giving creative ideas. The direct proportional influence illustrates that the employees with higher education level participate in the problem solving more than the employees with lower education level. This indicates the need for constant improving of organizational knowledge in purpose to include all the employees in the problem solving process by giving creative ideas.

It's been researched if the employees are motivated to share their knowledge with their colleagues in the organization. The significant correlation and direct proportional influence show that the older employees are more motivated to share their knowledge with their colleagues in the organization. 
There is significant correlation between the age of the employees and their opinion about the organization culture as a motivational factor for improvement of their knowledge. Because the influence is direct proportional, it can be said that the older employees recognize the importance of the organizational culture as a motivational factor for improvement of their knowledge.

Regarding the organizational culture, it's been also researched if it is motivational factor for sharing the knowledge. The results show significant correlation and direct proportional influence which indicate that the older employees recognize the organizational culture as a motivational factor for sharing their knowledge.

\section{Conclusion}

The knowledge management is considered to be a strategy which can meet the new conditions on the open market and can make the organization more competitive. The implementation and the effectiveness of this concept depend on several crucial factors such as organizational culture, human resource management, information technology.

The technological changes and the complex environment are extremely important in the telecommunication market. Also the legislation has opened the market and stimulates the competition. Regarding the dynamic changes on the telecommunication market the knowledge management is recognized as a strategy for acquiring competitive advantage.

Regarding the results of the survey, it can be concluded that the employees are aware of the increased competition occurred on the telecommunication market. It has to be noticed that the older employees recognize this change on the market. Also, the older employees recognize importance of the human resource management the competitive conditions on the market. The older employees are more motivated to share their knowledge with their colleagues in the organization. In spite of this, the younger employees emphasize the need of participation on the professional trainings and courses in purpose to improve and upgrade the knowledge and the skills. The importance of the knowledge is illustrated with the need of constant improvement of their knowledge outside of the field of their profession, which is also recognized by the younger employees.

Considering the age of the employees, results show that the younger employees are more interested in improving their knowledge, but the older employees also recognize the need for improvement of the knowledge. Having in mind that, managers should focus in motivating older employees in the organization in improving their knowledge by participating in professional trainings and courses.

Regarding the level of education, it can be concluded that respondents with higher level of education recognize that managers undertake activities to improve the knowledge and skills in the organization. Also the employees with higher education level participate in the problem solving more than the employees with lower education level.

The employees with the lower education level recognize the need of constant improvement of the knowledge in the field of their profession.

This results show clearly the awareness of the employees for constant improvement of the knowledge. This confirms the influence of the increased competitiveness of the open market and the need of knowledge management as a strategy for gaining competitive advantage.

Managers should focus on enhancing and upgrading the knowledge of the employees. They should be aware that employees are individuals with different age and level of education which indicate their different needs. Considering this, managers should have individual approach to each employee in purpose to explore the maximum of the human capital in the organization.

\section{References}

Argote L., McEvily B. and Reagans R., "Managing Knowledge in Organizations: An Integrative Framework and Review of Emerging Themes", Management Science Vol. 49, No. 4, Special Issue on Managing Knowledge in Organizations: Creating, Retaining, and Transferring Knowledge, Apr., 2003

Hansen M.T., Nohria N., Tierney T. "What's Your Strategy for Managing Knowledge", Harvard Business Review, march-april, 1999

Slavković M., "Korporativno upravljanje u tranziciji - vlasništvo, kontrola, menadžerske kompetencije", in Upravljanje znanjem i menadžerske kompetencije, Kragujevac: Ekonomski fakultet, 2006

Malhotra Y. "Knowledge Management in Inquiring Organizations", Proceeding of 2RD Americas Conference of Information System (Philosophy or Information Systems - in Track), Indianapolis 1997

Nikolic S., Miladonoski S., Tast J., "The globalization and the role of knowledge management the case of Republic of Macedonia", Journal of Advanced Research in Management, Volume IV, Issue 2(8) Winter 2013. 